\title{
BEM-ESTAR ANIMAL: CARACTERIZAÇÃO DA AMBIÊNCIA E DO MANEJO NA PRODUÇÃO E ABATE DE FRANGOS DE CORTE
}

\author{
Thais Fernandes Lima ${ }^{1}$ \\ Ariel Eurides Stella ${ }^{2}$ \\ Flávio Barbosa da Silva ${ }^{1}$ \\ Gracielle Teles Pádua ${ }^{1}$
}

\begin{abstract}
RESUMO
O modelo de produção mais utilizado na avicultura brasileira é o sistema de integração entre produtores e frigoríficos, o que permite a análise completa da cadeia produtiva e o estudo sistematizado da correlação entre estrutura, manejo e ambiente proporcionado às aves. Diante deste cenário, objetivou-se identificar os principais pontos vulneráveis da cadeia produtiva de frangos de corte relacionados à ambiência e ao manejo, caracterizando o nível de atendimento das normas de bem-estar animal (BEA) em estabelecimentos de criação e abate de aves, localizados no Sudoeste Goiano. Desta forma, procedeu-se à verificação de recomendações norteadas pelas diretrizes da Humane Farm Animal Care (HFAC) e da Royal Society for the Prevention of Cruelty to Animals (RSPCA) em vinte granjas e três frigoríficos distribuídos pela região amostrada. Os dados foram analisados pelo método descritivo. Como resultado, foram observadas falhas técnicas, de manejo e estruturais nas etapas pré-abate, bem como nos procedimentos industriais nos estabelecimentos avaliados, além da total ausência de enriquecimento ambiental.
\end{abstract}

Palavras-chave: Comportamento animal, Enriquecimento ambiental, Frigorífico.

\section{ANIMAL WELFARE: CHARACTERIZATION OF THE ENVIRONMENT AND HANDLING IN THE PRODUCTION AND SLAUGHTER OF BROILER}

\begin{abstract}
The production model most used in Brazilian poultry is the system of integration between farmers and slaughterhouses, which allows a complete analysis of the production system and a systematic study of the correlation between structure, management and the environment provided to the chickens. In view of this scenario, the objective was to identify the main vulnerable points in the broiler productive process associated to environment and handling, characterizing the level of compliance with animal welfare (WPA) standards in poultry breeding and slaughter establishments, located in the Southwest of Goiás. Thus, we proceeded to verify recommendations guided by the guidelines of the Humane Farm Animal Care (HFAC) and of the Royal Society for the Prevention of Cruelty to Animals (RSPCA) in twenty farms and three slaughterhouses distributed throughout the sampled region. The data were analyzed using the descriptive method. As a result, technical, management and structural failures were observed in the pre-slaughter stages, as well as in industrial procedures in the evaluated establishments, in addition to the total absence of environmental enrichment.
\end{abstract}

Keywords: Animal behaviour, Environmental enrichment, Slaughter house.

\footnotetext{
${ }^{1}$ Médica Veterinária, Mestre em Biociência Animal. Unidade de Ciências Agrárias, Universidade Federal de Jataí (UFJ). Campus Jatobá, Jataí, Goiás, Correspondência: thais.lima@agricultura.gov.br; thaisfl123@ hotmail.com.

${ }^{2}$ Docente Unidade de Ciências Agrárias, Universidade Federal de Jataí (UFJ)
} 


\title{
BIEN ESTAR ANIMAL: CARACTERIZACIÓN DEL MEDIO AMBIENTE Y GESTIÓN EN LA PRODUCCIÓN Y MATANZA DE POLLO
}

\begin{abstract}
RESUMEN
El modelo de producción más utilizado en la avicultura brasileñas es el sistema de integración entre productores y mataderos, que permite un análisis completo de la cadena de producción y un estudio sistemático de la correlación entre la estructura, el manejo y el ambiente proporcionado a las aves. Ante este escenario, el objetivo era identificar los principales puntos vulnerables en la cadena de producción de pollos de engorde relacionados con el ambiente y la gestión, caracterizando el nivel de cumplimiento de las normas de bienestar animal (BEA) en los establecimientos de cría y sacrificio de aves de engorde, ubicado en el suroeste de Goiás. Por lo tanto, procedimos a verificar las recomendaciones guiadas por las pautas de Humane Farm Animal Care (HFAC) y la Royal Society for the Prevention of Cruelty to Animals (RSPCA) en veinte granjas y tres mataderos distribuidos en toda la región muestreada. Los datos fueron analizados utilizando el método descriptivo. Como resultado, se observaron fallas técnicas, de gestión y estructurales en las etapas previas al sacrificio, así como en los procedimientos industriales en los establecimientos evaluados, además de la ausencia total de enriquecimiento ambiental.
\end{abstract}

Palabras clave: Comportamiento animal, enriquecimiento ambiental, matadero.

\section{INTRODUÇÃO}

Por volta do ano 2000, o dinamismo das emoções dos animais foi seriamente relacionado com o BEA (1). Thomas (2) definiu a preocupação atual com os animais de produção como uma fusão dos debates dos séculos XVIII e XIX. Para ele há o desejo de abolir o sofrimento desnecessário, aliando a isso a obtenção de ganhos econômicos com a adoção de medidas de BEA. Neste sentido, o Estado torna legítimo o abate dos animais para consumo, baseado na necessidade de alimentar o homem, o que não justifica o sofrimento aplicado aos animais de produção (3).

Contudo, é notável a adoção de formas de manejo cada vez mais tecnológicas nos sistemas de produção, que permitem grandes lotações de animais em ambientes artificiais, objetivando lucros financeiros na atividade. Tais sistemas podem criar condições negativas de vida, prejudicando o BEA e, consequentemente, a produtividade, conduzindo os animais ao desenvolvimento de estereotipias e ao sofrimento. Diante disso, estudos apontam a importância e a necessidade de se conhecer as características fisiológicas, mentais e comportamentais apresentadas pelos animais, no intuito de avaliar seu bem-estar (4).

Por meio de uma avaliação de parâmetros nos frigoríficos e granjas, objetivou-se identificar os pontos críticos relacionados ao BEA em cada fase do sistema produtivo de frangos de corte no sudoeste goiano.

\section{MATERIAL E MÉTODOS}

\section{Características dos estabelecimentos}

No presente estudo, as granjas amostradas diferenciavam entre si, basicamente, no que tange a circulação de ar (pressão positiva ou negativa) e controle atmosférico (dark house ou sistema semifechado). Os frigoríficos verificados apresentaram diferenças estruturais, no 
volume de produção e dimensões de área construída. No entanto, seguiam as mesmas normas e programas de autocontrole semelhantes, adaptados para a realidade de cada fábrica, salvo especificidades com relação a exigências específicas de mercados importadores.

\section{Amostragem e verificação dos parâmetros}

O presente estudo verificou vinte granjas e três frigoríficos distribuídos no Sudoeste Goiano, definidos para a pesquisa no início do projeto, tendo sido realizado ao longo do mês de junho do ano de 2018. Os comitês de pesquisa das indústrias foram consultados sobre a concordância da execução do projeto de pesquisa e foi assinado um termo de anuência. $\mathrm{O}$ roteiro de atividades e o agendamento das visitas nas granjas foram elaborados junto aos responsáveis pelas visitas técnicas, devido ao controle de fluxo de pessoas que deve ser seguido nos aviários.

Para a execução da busca ativa, foram elaborados dois questionários baseados nos padrões da Humane Farm Animal Care e diretrizes da Royal Society for the Prevention of Cruelty to Animals, a serem aplicados nas indústrias e nas granjas. Os questionários foram preenchidos após a observação dos procedimentos e verificação dos registros e controles solicitados aos granjeiros nos aviários e aos monitores da Garantia da Qualidade nos frigoríficos.

\section{Análise estatística}

Os dados resultantes foram analisados pelo método descritivo.

\section{RESULTADOS E DISCUSSÃO}

\section{Manejo e ambiência nas granjas}

As granjas avícolas verificadas atendiam, em parte, os quesitos recomendados internacionalmente, visando à adequação dos aviários para a promoção do BEA, como pode ser observado na Tabela 1. Foram observadas falhas na qualidade da cama nos aviários, compostas por maravalha (questões 18 a 26), relacionadas à ocorrência de lesões de pele, queimaduras e problemas locomotores nas aves. Souza et al. (5) verificaram vantagens na cama de areia em comparação à de maravalha, principalmente no que tange a problemas locomotores. Souza et al. (6) concluíram, por meio da adoção de escalas para dermatite de contato, sujeira nas penas e arranhões, que há correlação moderada entre a qualidade da cama e os indicadores avaliados.

A alta densidade dos alojamentos está diretamente relacionada ao conforto térmico e à circulação do ar (questões 32 a 36) e foi verificada em determinadas situações, como número de pintainhos maior do que o programado (questões 29 e 30). Jung e Knierim (7) conduziram um estudo em que as aves mantidas em alta densidade de alojamento apresentaram comportamento de bicar de penas. Há uma relação entre a temperatura e a umidade do ar considerada ideal para a manutenção da neutralidade térmica, que forma uma faixa de conforto para as aves e está intimamente relacionada com as suas reações fisiológicas (8). Neste sentido, Schiassi et al. (9), observaram comportamentos relacionados ao desconforto térmico dos frangos, como presença mais frequente ao bebedouro à temperatura de $33^{\circ} \mathrm{C}$, e agrupamento quando a temperatura foi reduzida para $24^{\circ} \mathrm{C}$.

A análise do estresse térmico pode envolver a observação direta do comportamento animal e dos parâmetros fisiológicos, associados a um diagnóstico do ambiente, conforme demonstrou Riber (10). O autor constatou que os frangos apresentaram a tendência de 
permanecer mais tempo sob as lâmpadas de luz fria, que proporcionavam maior conforto térmico. Contudo, o parâmetro mais indicado para se proceder à avaliação da condição térmica de um aviário é o índice de entalpia, calculado utilizando-se os valores da temperatura e da umidade do ar. A necessidade dos frangos varia sensivelmente desde a fase inicial de vida até a semana do abate, por isso existe um gráfico de entalpia para cada semana de vida dos animais (11). Os gráficos de entalpia eram utilizados nos frigoríficos e granjas amostradas.

Em uma metanálise envolvendo pesquisas realizadas ao longo de quinze anos, Baracho et al. (12) demonstraram que o desconforto pelo calor ou pelo frio afetou o desempenho das aves, e era verificado em faixas diferentes de umidade/temperatura ao se considerar distintas linhagens e idades.

Tabela 1. Parâmetros avaliados nas granjas - manejo e ambiência

\begin{tabular}{|c|c|c|}
\hline Questões & Adequado & $\begin{array}{c}\text { Parcial/ } \\
\text { inadequado }\end{array}$ \\
\hline 1. Existe alimentação adequada à idade e ao estágio de produção? & $20(100 \%)$ & $0(0 \%)$ \\
\hline 2. Todas as aves se alimentam sem competição indevida? & $14(70 \%)$ & $6(30 \%)$ \\
\hline 3. As aves tem acesso fácil ao alimento? & $20(100 \%)$ & $0(0 \%)$ \\
\hline 4. Os registros da alimentação estão disponíveis para inspeção? & $20(100 \%)$ & $0(0 \%)$ \\
\hline 5. Existem produtos de origem animal na alimentação? & $20(100 \%)$ & $0(0 \%)$ \\
\hline 6. Existem produtos como promotores de crescimento na ração? & $0(0 \%)$ & $20(100 \%)$ \\
\hline 7. Existem produtos como antibióticos na ração? & $20(100 \%)$ & $0(0 \%)$ \\
\hline $\begin{array}{l}\text { 8. A alimentação é armazenada em locais apropriados (limpos, secos, bem conservados e a prova } \\
\text { de contaminantes)? }\end{array}$ & $20(100 \%)$ & $0(0 \%)$ \\
\hline 9. Os frangos tem acesso contínuo à água? & $20(100 \%)$ & $0(0 \%)$ \\
\hline 10. A quantidade mínima de bebedouros é respeitada (pendular: 1/100, nipple: 1/20, taça: $1 / 28$ )? & $20(100 \%)$ & $0(0 \%)$ \\
\hline 11. O derramamento de água é prevenido? & $16(80 \%)$ & $4(20 \%)$ \\
\hline 12. Existe suprimento emergencial de água (mínimo de 24 h)? & $20(100 \%)$ & $0(0 \%)$ \\
\hline 13. Existe na granja um registro com informações de instalação? & $16(80 \%)$ & $4(20 \%)$ \\
\hline 14. As instalações estão bem preservadas? & $15(75 \%)$ & $5(25 \%)$ \\
\hline 15. As aves podem ser facilmente observadas pelos tratadores? & $20(100 \%)$ & $0(0 \%)$ \\
\hline 16. As instalações elétricas estão bem isoladas e protegidas? & $20(100 \%)$ & $0(0 \%)$ \\
\hline 17. A área externa está limpa e com plantas podadas (sem abrigo para pássaros e roedores)? & $14(70 \%)$ & $6(30 \%)$ \\
\hline 18. Piso adequado (completamente coberto com cama e sem rachaduras no chão)? & $15(75 \%)$ & $5(25 \%)$ \\
\hline 19. A cama é de boa qualidade (limpa e seca) e material adequado? & $15(75 \%)$ & $5(25 \%)$ \\
\hline 20. A cama tem espessura suficiente para a diluição dos excrementos? & $15(75 \%)$ & $5(25 \%)$ \\
\hline 21. Os pés das aves estão livres de contaminação fecal excessiva? & $15(75 \%)$ & $5(25 \%)$ \\
\hline 22. É permitido que as aves tomem "banho de areia"? & $0(0 \%)$ & $20(100 \%)$ \\
\hline 23. Existe piso com arame ou ripas? & $20(100 \%)$ & $0(0 \%)$ \\
\hline 24. A cama nova é armazenada corretamente (área limpa e livre de pragas)? & $20(100 \%)$ & $0(0 \%)$ \\
\hline 25. A cama está contaminada (úmida, endurecida, acarídeos)? & $14(70 \%)$ & $6(30 \%)$ \\
\hline 26. Na opinião do funcionário responsável a qualidade da cama influencia o BEA? & $20(100 \%)$ & $0(0 \%)$ \\
\hline 27. Existe o período mínimo de 6 h de escuridão a cada 24 h? & $20(100 \%)$ & $0(0 \%)$ \\
\hline 28. Existem registros disponíveis dos padrões de iluminação? & $17(85 \%)$ & $3(15 \%)$ \\
\hline $\begin{array}{l}\text { 29. A densidade do alojamento é adequada (as aves conseguem permanecer de pé, se virar e } \\
\text { esticar as suas asas sem dificuldades)? }\end{array}$ & $17(85 \%)$ & $3(15 \%)$ \\
\hline 30. Existe registro disponível para o inspetor (área total do piso, número de aves)? & $20(100 \%)$ & $0(0 \%)$ \\
\hline $\begin{array}{l}\text { 31. Existe registro disponível para o inspetor (mortalidade diária, número de aves descartadas, } \\
\text { peso médio na idade do abate)? }\end{array}$ & $20(100 \%)$ & $0(0 \%)$ \\
\hline 32. Poluentes aéreos (nuvem de poeira) são desagradavelmente percebidos no alojamento? & $15(75 \%)$ & $5(25 \%)$ \\
\hline 33. Existem registros disponíveis, quinzenais, da proporção de amônia à altura das aves? & $0(0 \%)$ & $20(100 \%)$ \\
\hline 34. Existem sistemas de alarme nos equipamentos de ventilação? & $20(100 \%)$ & $0(0 \%)$ \\
\hline 35. As instalações minimizam os riscos de superaquecimento? & $20(100 \%)$ & $0(0 \%)$ \\
\hline 36. Existe um sistema de resfriamento tipo evaporativo? & $20(100 \%)$ & $0(0 \%)$ \\
\hline 37. Existe enriquecimento ambiental? & $0(0 \%)$ & $20(100 \%)$ \\
\hline 38. O ambiente para os pintos é adequado, e é ajustado à medida que estes crescem? & $20(100 \%)$ & $0(0 \%)$ \\
\hline $\begin{array}{l}\text { 39. Existe comunicação entre o setor da agropecuária do frigorífico e a granja, na ocorrência de } \\
\text { queimaduras e calos de pé e peito nos frangos, no momento do abate? }\end{array}$ & $14(70 \%)$ & $6(30 \%)$ \\
\hline
\end{tabular}

Lima TF, Stella AE, Silva FB, Pádua GT. Bem-estar animal: Caracterização da ambiência e do manejo na produção e abate de frangos de corte. Vet. e Zootec. 2020; 27: 001-015. 
A ventilação e a densidade interferem também na concentração de gases nocivos no aviário, como amônia, gás sulfídrico e gás carbônico. A produção desses gases é uma condição característica da produção animal e está relacionada com o BEA, pois prejudica o sistema imune, o conforto e o desempenho das aves, além de provocar irritações e inflamações no trato respiratório e nas estruturas oculares. A reutilização da cama em lotes sucessivos de aves promove maior liberação de amônia, devido à elevação de $\mathrm{pH}$ e umidade resultante do acúmulo de excrementos (13). Hernandez et al. (14) verificaram altas concentrações de amônia dentro de aviários com pouca ventilação. Batista e Neitzel (15) afirmaram que a velocidade do ar e o posicionamento dos ventiladores e exautores favoreceram a qualidade do ar dentro dos galpões. Ro et al. (16) concluíram que, o uso de amortecedores vegetais, como árvores, arbustos e gramas ao redor dos exaustores dos aviários pode aumentar a dispersão e reduzir a concentração de gases dentro dos galpões. Para Zarnab et al. (17), a aplicação de modificadores ambientais, como o silicato de alumínio pode reduzir as concentrações atmosféricas de amônia nos aviários. Nenhuma granja avaliada neste estudo possuía registros de concentração de amônia ao nível dos frangos (questão 33).

Problemas estruturais e de manutenção foram notados em alguns aviários, como vazamentos de água provenientes dos bebedouros gotejando diretamente na cama (questão 11); lonas danificadas, permitindo a entrada de luz e ar quente; fluxo inadequado de caminhões de transporte, retardando o processo de apanha; e mau funcionamento de equipamento de desinfecção na entrada da granja (questões 13 a 18). As aves se mostraram mais agitadas nos aviários que permitiam a entrada de luz natural, devido a avarias nas lonas ou ao uso de cortinas azuis ou amarelas, sendo as lonas pretas (dark house) mais eficientes neste sentido (questões 27 e 28). Validando tal observação, Rault et al. (18) verificaram que os frangos de corte se mostraram mais calmos e se desenvolveram melhor quando mantidos a uma menor intensidade luminosa. De acordo com Oliveira e Lara (19), a duração do fotoperíodo pode proporcionar saúde, bem-estar e melhorar o desempenho dos frangos, que necessitam de um período mínimo de escuro para descansar e se restabelecer do estresse causado pelo ambiente artificial.

Nos aviários comerciais amostrados, ficou evidente que as aves eram impedidas de expressar seu comportamento natural, diante da artificialidade do ambiente, sem nenhum enriquecimento ambiental (questões 22 e 37). A dificuldade em fornecer os recursos ambientais aos frangos, verificada durante a pesquisa é a redução de densidade de alojamento, devido ao espaço ocupado pelos objetos. No entanto, os benefícios proporcionados pelo ambiente adaptado às necessidades das aves devem ser considerados, além dos efeitos benéficos para o BEA proporcionados pela menor densidade de animais nos aviários. Neste sentido, Jones et al. (20) verificaram que, de oito propostas de enriquecimento testadas, apenas o distanciamento entre bebedouros e comedouros e a redução da lotação refletiram retorno financeiro para o produtor. Portanto, é necessário haver um subsídio ou um pagamento maior pelo produto para incentivar a implantação desses recursos.

Segundo Broom (4), os animais devem dispor de espaço e liberdade para escolher a postura desejada e expressarem seu comportamento natural (questões 29 a 31). Seus sentimentos podem ser mensurados por meio do teste de esquiva, que dá indicações de BEA no ambiente, e pelo teste de preferência, que é um indicador de felicidade. Paul et al. (21) analisaram o teste de Preferência de Local Condicionado em frangos, e concluíram que sua aplicação pode estabelecer uma preferência aprendida ou aversão ao ambiente em que o estímulo foi vivenciado.

Como alternativa à artificialidade dos ambientes, Ricci et al. (22) sugerem o uso de recursos de enriquecimento ambiental, que permita aos frangos a expressão de comportamentos próximos ao natural, reduzindo estímulos estressores e promovendo o BEA. Comparando as reações comportamentais de frangos de corte a ambientes enriquecidos com

Lima TF, Stella AE, Silva FB, Pádua GT. Bem-estar animal: Caracterização da ambiência e do manejo na produção e abate de frangos de corte. Vet. e Zootec. 2020; 27: 001-015. 
outros criados em locais típicos, porém manipulados, Tahamtani et al. (23) concluíram que o uso de recursos que aumentam a complexidade ambiental pode reduzir o medo nos frangos, evitando a histeria e mortes por amontoamento. Reforçando a ideia anterior, Bach et al. (24) afirmaram que a oferta de enriquecimento ambiental e a manipulação de recursos presentes nos alojamentos aumentam a atividade dos frangos de corte, consequentemente reduzindo as lesões de contato e os problemas locomotores. Avaliando os efeitos da utilização de painéis verticais e distanciamento dos recursos presentes em aviários na produção de frangos, Pedersen et al. (25) observaram que os tratamentos analisados proporcionaram fortalecimento e alongamento dos ossos e músculos das pernas. Baxter et al. (26) não encontraram relação entre o uso de poleiros em forma de plataforma com a locomoção das aves, contudo, observaram menos tentativas de esquiva. Em um estudo de revisão sobre enriquecimento ambiental e a saúde das pernas dos frangos, Pedersen e Forkman (27) identificaram evidências de que determinados recursos, como menor densidade de lotação, programa de iluminação, uso de fardos de feno e distanciamento dos comedouros e bebedouros afetam positivamente a mobilidade das aves e o BEA.

Após o abate, a análise do aspecto das lesões observadas nas aves permite identificar se elas ocorreram antes ou após a morte do animal, e se é uma ferida recente ou antiga. De posse da evidência de que desvios de BEA ocorreram na granja ou no transporte, a comunicação entre os responsáveis dos setores deveria ser prática rotineira, no intuito de detectar falhas e promover melhorias. Durante a pesquisa, notou-se que esse não é um procedimento regular (questão 39).

\section{Gestão, saúde e transporte nas granjas}

A inexistência de planos de ação emergenciais foi constatada, como pode ser observado na Tabela 1 (questão 12) e na Tabela 2 (questão 41). Algumas propriedades dependiam do suporte de caminhões-pipa na falta de água. Granjas mais antigas não possuíam geradores e outras não mantinham peças para reposição em estoque, lapso que pode ocasionar alta mortalidade de frangos por calor excessivo e de pintainhos por falta de aquecimento.

Com relação aos pontos críticos observados na apanha dos frangos, o tempo estabelecido para a finalização de um carregamento era curto, o que dificultava $o$ procedimento que deve evitar o estresse e a histeria nas aves, e suas consequentes lesões. Ainda que as equipes de apanha tenham se mostrado sincronizadas, composta por funcionários habilidosos, o prazo estipulado para a conclusão da atividade, de forma a atender a logística de abate, dificultou o cumprimento de todas as diretrizes de BEA (Tabela 2, questões 48 a 57). Nas granjas amostradas era realizada a apanha manual, pelo dorso, com as duas mãos imobilizando as asas, já que a apanha automática não é utilizada no Brasil. De toda forma, comparando os métodos de apanha manual e mecanizada, Wolff et al. (28) concluíram que ambas as técnicas necessitam de ajustes e modificações, no que diz respeito ao BEA.

A captura das aves pelo dorso é o método menos estressante, pois impede o bater de asas e respeita a zona de fuga do animal. Procedimentos como, cortinas fechadas, captura de uma ave por vez e o acondicionamento cuidadoso dentro das gaiolas podem melhorar o comportamento dos frangos, diminuindo o risco de acidentes, afetando positivamente o BEA. Além disso, um tempo de carregamento prolongado sem períodos de descanso influencia diretamente o bem-estar dos apanhadores por se tratar de uma atividade de grande esforço físico, afetando o comportamento e bem-estar das aves (29).

No presente estudo foi observado que a densidade dentro das gaiolas de transporte deve permitir que todas as aves se deitem ao mesmo tempo, sem se sobrepor umas às outras, evitando prensar os frangos entre as caixas. Além disso, foi verificado que o acondicionamento das aves nas caixas pode causar estímulos estressores e lesões nos animais, 
devido à movimentação e à técnica de apanha. De acordo com Braga et al. (30), muitas vezes a lotação de aves nas gaiolas ultrapassa as recomendações devido a estratégias financeiras, fato que prejudica o BEA, promove estresse térmico, favorece o aparecimento de lesões e aumenta a mortalidade. Uma medida que poderia proporcionar conforto térmico, mas que não é praticada seria diminuir a densidade de frangos nas gaiolas em climas quentes. O que foi observado neste estudo é que essa densidade é calculada pelo peso dos animais, independentemente de qualquer outro fator relevante (questões 58 a 74).

Tabela 2. Parâmetros avaliados nas granjas - gestão, saúde e transporte

\begin{tabular}{|c|c|c|}
\hline Questões & Adequado & $\begin{array}{c}\text { Parcial/ } \\
\text { inadequado }\end{array}$ \\
\hline 40. Existem registros dos dados de uso de medicamentos? & $20(100 \%)$ & $0(0 \%)$ \\
\hline 41. Existe um plano de ação de emergência (incêndio, inundação, falta de energia)? & $0(0 \%)$ & $20(100 \%)$ \\
\hline 42. Os lotes são inspecionados pelos menos duas vezes por dia? & $20(100 \%)$ & $0(0 \%)$ \\
\hline $\begin{array}{l}\text { 43. Os frangos doentes, com ferimentos ou fraturas são isolados e tratados e/ou sacrificados de forma } \\
\text { humanitária? }\end{array}$ & $15(75 \%)$ & $5(25 \%)$ \\
\hline 44. As aves são debicadas? & $20(100 \%)$ & $0(0 \%)$ \\
\hline 45. Os alojamentos são limpos e desinfetados entre os lotes? & $20(100 \%)$ & $0(0 \%)$ \\
\hline 46. Há condições de abate humanitário com pessoal treinado? & $20(100 \%)$ & $0(0 \%)$ \\
\hline 47. As carcaças são descartadas adequadamente? & $20(100 \%)$ & $0(0 \%)$ \\
\hline 48. As aves visivelmente debilitadas na hora da apanha são transportadas para o frigorífico? & $15(75 \%)$ & $5(25 \%)$ \\
\hline $\begin{array}{l}\text { 49. Existe um membro da equipe de apanha responsável pela supervisão e monitoramento do bom } \\
\text { andamento em relação aos cuidados com os animais? }\end{array}$ & $20(100 \%)$ & $0(0 \%)$ \\
\hline 50. Há tempo suficiente para garantir que as aves sejam manejadas com cuidado? & $6(30 \%)$ & $14(70 \%)$ \\
\hline 51. As aves tem acesso à água até o momento da apanha? & $20(100 \%)$ & $0(0 \%)$ \\
\hline 52. O tempo que leva da apanha até o processamento excede 12 h? & $20(100 \%)$ & $0(0 \%)$ \\
\hline $\begin{array}{l}\text { 53. Todos os comedouros, bebedouros e outros obstáculos são suspensos ou removidos na hora da } \\
\text { apanha? }\end{array}$ & $20(100 \%)$ & $0(0 \%)$ \\
\hline 54. A apanha é efetuada sob pouca iluminação? & $15(75 \%)$ & $5(25 \%)$ \\
\hline 55. Os animais são apanhados individualmente e carregados pelas duas pernas? & $16(80 \%)$ & $4(20 \%)$ \\
\hline 56. São carregadas até no máximo três aves em cada mão? & $20(100 \%)$ & $0(0 \%)$ \\
\hline 57. Medidas são adotadas para evitar o amontoamento das aves? & $20(100 \%)$ & $0(0 \%)$ \\
\hline $\begin{array}{l}\text { 58. O transporte com as caixas tem ventilação adequada e protegem as aves de condições climáticas } \\
\text { inadequadas? }\end{array}$ & $20(100 \%)$ & $0(0 \%)$ \\
\hline 59. As caixas são limpas e bem conservadas? & $0(0 \%)$ & $20(100 \%)$ \\
\hline 60. Há protrusões cortantes nas caixas? & $0(0 \%)$ & $20(100 \%)$ \\
\hline $\begin{array}{l}\text { 61. Os apanhadores suspendem as caixas (com as aves) acima da altura de suas cabeças quando } \\
\text { carregando as caixas no veículo? }\end{array}$ & $0(0 \%)$ & $20(100 \%)$ \\
\hline 62. As aves são jogadas nas caixas? & $16(80 \%)$ & $4(20 \%)$ \\
\hline 63. Para a apanha, a ave é suspensa pelo dorso, com as duas mãos? & $14(70 \%)$ & $6(30 \%)$ \\
\hline 64. As aves são suspensas pela asa ou pelo pescoço? & $20(100 \%)$ & $0(0 \%)$ \\
\hline 65. As aves são apanhadas uma por vez? & $0(0 \%)$ & $20(100 \%)$ \\
\hline 66. A densidade é reduzida quando as aves são transportadas durante clima quente (acima de $25^{\circ} \mathrm{C}$ )? & $0(0 \%)$ & $20(100 \%)$ \\
\hline 67. A base das caixas fixas previne que as excretas caiam sobre as aves abaixo delas? & $0(0 \%)$ & $20(100 \%)$ \\
\hline 68. O nível de mortalidade durante o transporte está dentro do máximo permitido (1\%)? & $20(100 \%)$ & $0(0 \%)$ \\
\hline $\begin{array}{l}\text { 69. O tempo entre o início do carregamento e a conclusão do descarregamento das caixas é inferior a } \\
10 \text { horas? }\end{array}$ & $20(100 \%)$ & $0(0 \%)$ \\
\hline $\begin{array}{l}\text { 70. O nível de ruídos (qualquer tipo) é minimizado durante o carregamento, transporte e } \\
\text { descarregamento? }\end{array}$ & $14(70 \%)$ & $6(30 \%)$ \\
\hline $\begin{array}{l}\text { 71. Nos períodos de clima quente, os frangos são transportados à noite ou nas horas mais frescas do } \\
\text { dia? }\end{array}$ & $0(0 \%)$ & $20(100 \%)$ \\
\hline $\begin{array}{l}\text { 72. O veículo de transporte está equipado com cortinas apropriadas que possam ser abertas ou } \\
\text { fechadas por um único operador? }\end{array}$ & $0(0 \%)$ & $20(100 \%)$ \\
\hline $\begin{array}{l}\text { 73. Quando o clima é quente, um corredor central é deixado livre (no caminhão), para permitir maior } \\
\text { ventilação? }\end{array}$ & $20(100 \%)$ & $0(0 \%)$ \\
\hline 74. Existe algum monitoramento de temperatura e umidade nos veículos de transporte? & $0(0 \%)$ & $20(100 \%)$ \\
\hline
\end{tabular}

\section{Parâmetros de BEA nos frigoríficos}

O índice de BEA nas etapas que antecedem o abate pode influenciar a porcentagem de aves que chegam mortas ao frigorífico, e deve ser utilizado como ferramenta para alcançar 
melhorias nas condições de vida dos frangos (31). Apontamento semelhante foi realizado por Grandin (32) ao afirmar que, a avaliação das condições físicas e fisiológicas das aves na chegada ao frigorífico é importante para a identificação de falhas de BEA na criação dos animais.

Após a chegada das aves ao frigorífico, recomenda-se que o abate seja imediato. Não sendo possível, é permitida a espera das aves em área coberta, com sistemas de ventilação e umidificação (Tabela 1, questões 3, 7 e 8). A recomendação internacional é que o tempo de espera não ultrapasse quatro horas e o jejum seja de no máximo 12 horas desde a granja até o abate (33). Reforçando a imprescindibilidade de se respeitar o tempo de jejum, De Jong et al. (34) verificaram que os frangos submetidos à restrição alimentar apresentaram comportamentos característicos de fome, como agitação, bicar o comedouro vazio, bicar e ciscar a cama e beber mais água, ao contrário das aves com alimentação ad libitum.

Nos frigoríficos amostrados, mesmo diante de grande variação de temperatura ao longo do dia, foi mantido o ambiente adequado no galpão, tendo sido observada falha no uso da nebulização, resultando em grande saturação do ar, com consequente desconforto para as aves. Vieira et al. (35) verificaram a importância da climatização do galpão de espera, que deve proporcionar conforto térmico às aves. Segundo os autores, as melhores condições foram observadas à temperatura entre $21^{\circ} \mathrm{C}$ e $24^{\circ} \mathrm{C}$, com umidade relativa do ar de $70 \%$ e descanso de pelo menos duas horas. Tavernari et al. (36) afirmaram que a programação do abate deve levar em consideração a distância das granjas ao frigorífico e seguir a ordem de chegada de cada carga, de forma a cumprir o recomendado para o tempo de espera e de jejum hídrico, confirmando a importância desta diretriz.

Dos três frigoríficos verificados, dois apresentaram falhas no recolhimento das aves soltas no setor de descarregamento, resultando na ocorrência de animais prensados nas esteiras e fraturados por caírem dos caminhões e das plataformas, além do risco de atropelamento (Tabela 3). Houve demora na apreensão das aves soltas, porque não era designado funcionário especificamente para esta função, sendo responsável pelo recolhimento qualquer colaborador do setor que presenciasse ave solta. Muitas gaiolas chegavam ao abatedouro sem tampa ou abertas (5\%), devido a falhas das equipes de apanha, trepidações no transporte e reposição de gaiolas danificadas (questões 19 e 34b). De acordo com Tavernari et al. (36), no abatedouro, as aves devem ser descarregadas dos caminhões de forma suave, sem movimentos bruscos, manual ou automaticamente, sendo alocadas imediatamente nas esteiras que as conduzirão ao abate.

Em dois frigoríficos, as linhas de pendura apresentavam curvas antes de chegar às cubas de insensibilização (questão 18). Sendo assim, as aves perdiam o contato com a proteção de peito, se agitavam e batiam as asas, devido à velocidade das nóreas, especialmente quando as linhas de abate não estavam cheias, provocando fraturas e contusões, e influenciando a eficiência do atordoamento. O processo de pendura dos frangos era automatizado e realizado com rapidez. As aves eram penduradas pelos dois pés, para que a corrente elétrica da etapa de insensibilização atravessasse eficientemente o corpo dos animais.

Segundo Fuseini et al. (37), a posição de inversão das aves na pendura compromete o BEA, devido ao desconforto físico e respiratório. Além disso, o procedimento mal realizado, pendurando o frango por apenas um pé pode provocar dor e fraturas (38). As diretrizes para a etapa de pendura consistem em número adequado de funcionários e medidas que evitem a agitação das aves, como barra de proteção de peito, baixa luminosidade e redução de ruídos (33). As nóreas nos frigoríficos são automáticas, portanto, possuem motores ruidosos e no setor de pendura das aves não é diferente. Portanto, lança-se mão do uso de luz azul e baixa luminosidade, no intuito de acalmar os frangos e evitar que se debatam (questões 11 a 22). Os desvios que ocorreram na pendura, em dois estabelecimentos de abate tiveram relação com a força excessiva usada pelos funcionários e frangos pendurados por apenas um pé (questão 
34c). Como demonstrado na Tabela 3, os demais quesitos recomendados pela HFAC (38) e RSPCA (39) foram atendidos de forma semelhante entre os abatedouros amostrados, inclusive durante os procedimentos de insensibilização e sangria (questões 23 a 34).

A insensibilização é a operação que conduz o animal rapidamente à inconsciência, mantendo suas funções vitais até o momento da sangria. O método considerado mais adequado é a eletronarcose sob imersão em líquido (40). Parâmetros elétricos como, frequência, tensão, tipos de ondas e intensidade da corrente elétrica devem ser ajustados ao tamanho e peso das aves (41). Esses parâmetros não possuem valores determinados por lei, no entanto, as três indústrias amostradas utilizavam corrente contínua pulsada e alta frequência na insensibilização por eletronarcose.

Tabela 3. Parâmetros avaliados nos frigoríficos

\begin{tabular}{|c|c|c|}
\hline Questões & Adequado & $\begin{array}{c}\text { Parcial/ } \\
\text { Inadequado }\end{array}$ \\
\hline $\begin{array}{l}\text { 1. Lesões por queimaduras nos joelhos e pés são observadas frequentemente nas carcaças } \\
\text { (indicativo de cama úmida e excesso de amônia)? }\end{array}$ & $3(100 \%)$ & $0(0 \%)$ \\
\hline $\begin{array}{l}\text { 2. As aves são observadas quanto à mortalidade, saúde de pés e pernas, pododermatites e pústulas } \\
\text { no peito? }\end{array}$ & $3(100 \%)$ & $0(0 \%)$ \\
\hline 3. Existe abate imediato (sofrimento por estresse e ferimentos)? & $3(100 \%)$ & $0(0 \%)$ \\
\hline 4. Existe um encarregado pelo BEA durante o processamento? & $3(100 \%)$ & $0(0 \%)$ \\
\hline 5. As aves estão inconscientes durante a operação de abate? & $3(100 \%)$ & $0(0 \%)$ \\
\hline 6. Há um programa de treinamento de BEA para os funcionários do abate? & $3(100 \%)$ & $0(0 \%)$ \\
\hline 7. A área de espera é ambientalmente controlada? & $3(100 \%)$ & $0(0 \%)$ \\
\hline 8. O abate ocorre até no máximo 4 horas após a chegada das aves? & $3(100 \%)$ & $0(0 \%)$ \\
\hline 9. Existe um gerador disponível em casos de falha ou emergência? & $3(100 \%)$ & $0(0 \%)$ \\
\hline $\begin{array}{l}\text { 10. Existe um registro de aves mortas que é relatado ao encarregado pelo BEA e ao gerente da } \\
\text { granja? }\end{array}$ & $3(100 \%)$ & $0(0 \%)$ \\
\hline 11. Há pessoas suficientes presentes na linha de pendura? & $3(100 \%)$ & $0(0 \%)$ \\
\hline 12. Os ganchos são de tipo e tamanho adequado? & $3(100 \%)$ & $0(0 \%)$ \\
\hline 13. A velocidade da linha é adequada? & $3(100 \%)$ & $0(0 \%)$ \\
\hline 14. As aves são penduradas pelas 2 pernas, com cada perna em um gancho? & $3(100 \%)$ & $0(0 \%)$ \\
\hline 15. Existe barra de peito? & $3(100 \%)$ & $0(0 \%)$ \\
\hline 16. Há redução de ruídos? & $0(0 \%)$ & $3(100 \%)$ \\
\hline 17. Há baixa intensidade de luz? & $3(100 \%)$ & $0(0 \%)$ \\
\hline 18. Existem curvas entre a linha de pendura e a insensibilização? & $1(33 \%)$ & $2(67 \%)$ \\
\hline 19. As aves soltas são imediatamente levadas à linha de pendura? & $1(33 \%)$ & $2(67 \%)$ \\
\hline 20. As aves soltas feridas são abatidas fora da linha? & $3(100 \%)$ & $0(0 \%)$ \\
\hline 21. As aves ficam suspensas por mais de 90 segundos antes da insensibilização? & $3(100 \%)$ & $0(0 \%)$ \\
\hline 22. As aves ainda não insensibilizadas conseguem ver as aves mortas? & $3(100 \%)$ & $0(0 \%)$ \\
\hline 23. As cabeças de todas as aves tem contato efetivo com a cuba de água? & $3(100 \%)$ & $0(0 \%)$ \\
\hline 24. As aves recebem choques antes da insensibilização? & $3(100 \%)$ & $0(0 \%)$ \\
\hline 25. A cuba é provida de amperímetro? & $3(100 \%)$ & $0(0 \%)$ \\
\hline $\begin{array}{l}\text { 26. Os equipamentos de insensibilização e sangria são monitorados/testados na frequência } \\
\text { estipulada? }\end{array}$ & $3(100 \%)$ & $0(0 \%)$ \\
\hline $\begin{array}{l}\text { 27. Se a linha de abate parar por mais de três minutos, as aves entre o ponto de pendura e do abate } \\
\text { são removidas? }\end{array}$ & $3(100 \%)$ & $0(0 \%)$ \\
\hline $\begin{array}{l}\text { 28. Se a linha de abate parar por mais de três minutos, as aves já insensibilizadas são } \\
\text { humanitariamente abatidas? }\end{array}$ & $3(100 \%)$ & $0(0 \%)$ \\
\hline $\begin{array}{l}\text { 29. Todas as aves que saem da insensibilização são examinadas para garantir que elas estão } \\
\text { efetivamente inconscientes ou mortas? }\end{array}$ & $3(100 \%)$ & $0(0 \%)$ \\
\hline 30. A equipe é treinada e reconhece os sinais de insensibilização eficaz? & $3(100 \%)$ & $0(0 \%)$ \\
\hline 31. As aves estão mortas antes de entrarem no tanque de escaldagem? & $3(100 \%)$ & $0(0 \%)$ \\
\hline 32. Transcorre mais que $10 \mathrm{~s}$ entre a insensibilização e o corte no pescoço? & $3(100 \%)$ & $0(0 \%)$ \\
\hline $\begin{array}{l}\text { 33. O tempo mínimo de sangria ( } 90 \text { segundos) é respeitado para garantir a morte do animal antes do } \\
\text { tanque de escaldagem? }\end{array}$ & $3(100 \%)$ & $0(0 \%)$ \\
\hline \multicolumn{3}{|l|}{$\begin{array}{l}\text { 34. Durante o período observado, houve descumprimento do procedimento escrito de bem-estar } \\
\text { animal? Em qual etapa ocorreu desvio? }\end{array}$} \\
\hline a. $\quad$ Recepção & $3(100 \%)$ & $0(0 \%)$ \\
\hline b. Descarregamento & $0(0 \%)$ & $3(100 \%)$ \\
\hline c. Pendura & $1(33 \%)$ & $2(67 \%)$ \\
\hline d. Insensibilização & $3(100 \%)$ & $0(0 \%)$ \\
\hline
\end{tabular}

Lima TF, Stella AE, Silva FB, Pádua GT. Bem-estar animal: Caracterização da ambiência e do manejo na produção e abate de frangos de corte. Vet. e Zootec. 2020; 27: 001-015. 


\begin{tabular}{|c|c|c|c|}
\hline & Maus tratos & $3(100 \%)$ & $0(0 \%)$ \\
\hline f. & Sangria & $3(100 \%)$ & $0(0 \%)$ \\
\hline & Escaldagem & $3(100 \%)$ & $0(0 \%)$ \\
\hline
\end{tabular}

De acordo com Ludtke et al. (38), para uma eficiente insensibilização, a cabeça dos frangos deve entrar em contato com a água do tanque, evitando-se o pré-choque e a tentativa do animal de se esquivar. Em contrapartida, Fuseini et al. (37) relataram que muitos pesquisadores não aprovam tal método, a começar pelas atividades que antecedem $o$ atordoamento em si, como a retirada das aves do interior das gaiolas, a pendura pelos pés com a cabeça imersa em cuba com água e a pressão exercida nas coxas pelos ganchos. De acordo com os autores, ainda há a possibilidade de as aves retomarem a consciência durante a sangria, ou após o sangramento mal feito. Para Yardimci (42), a corrente elétrica provoca contrações e dor ao atravessar o corpo dos animais, mesmo que não seja evidente. Segundo o autor, o corte dos principais vasos do pescoço sem a aplicação do atordoamento prévio promove isquemia cerebral e leva o animal à analgesia.

A fim de avaliar a eficiência da insensibilização de frangos por eletronarcose, Barbosa et al. (43) realizaram testes durante os quais observaram que o atordoamento não foi eficaz, devido às diferentes faixas de peso do lote. Os autores concluíram que 5\% das aves não foram adequadamente insensibilizadas, apresentando bater coordenado de asas, respiração rítmica e cabeça arqueada, parâmetros utilizados para avaliar se o animal está inconsciente. Para Mackie e Mckeegana (44) a insensibilização por baixa pressão atmosférica, com redução dos níveis de oxigênio, atende de forma mais eficiente ao BEA do que o uso de gás carbônico (CO2). Pinto et al. (45) observaram menores valores de glicose e corticosterona, indicadores de estresse, no sangue das aves insensibilizadas por $\mathrm{CO} 2$, em comparação com animais atordoados por eletronarcose.

$\mathrm{O}$ atordoamento por baixa frequência leva o animal à morte antes da sangria, o que contraria a legislação brasileira e os requisitos religiosos do abate Halal, realizado por meio de corte transversal no pescoço, de modo a atingir as jugulares, as carótidas e a traqueia (46). $\mathrm{O}$ uso da alta frequência permite o retorno da ave à consciência após alguns segundos, de forma que a sangria deve ser realizada imediatamente após a insensibilização (47).

O processo de sangria, última etapa em que o BEA pode ser considerado, consiste no corte transversal das veias jugulares e das artérias carótidas, através de corte manual com faca ou por disco automático de corte e deve promover a hipovolemia nos animais em um período mínimo de três minutos (40). Nesse estudo, a eficiência do tempo de sangria era monitorada na entrada do tanque de escaldagem, bem como a presença de aves vivas ou mal sangradas (questões 31, 33 e 34g). Não existe consenso acerca do método adequado de abate de animais de produção, nem sobre a possibilidade da incisão no pescoço provocar dor e estresse, mediante insensibilização ou não. De acordo com Zulkifli et al. (48), o abate Halal, com ou sem atordoamento não altera significativamente os parâmetros fisiológicos dos frangos. Aghwan et al. (49) observaram resultados semelhantes e afirmaram que a sangria por meio de degola, precedida de atordoamento ou não, promove o BEA se realizado adequadamente. Neste sentido, Wigham et al. (50) concluíram em seu experimento que treinamentos realizados com os operadores em frigoríficos de abate de frangos apresentaram efeitos benéficos sobre o procedimento de corte do pescoço. Além disso, verificaram movimentos mais suaves dos trabalhadores na pendura das aves, melhorias nos padrões de atordoamento e na ocorrência de pré-choque.

\section{CONCLUSÕES}

As instalações comerciais e os equipamentos utilizados nos aviários e abatedouros visitados procuravam favorecer os índices zootécnicos e facilitar o manejo dos frangos, no 
entanto, forneciam um ambiente artificial aos animais, fator que impossibilitava a expressão do comportamento natural. Não foi observado enriquecimento ambiental em nenhuma das granjas avaliadas. Diante desta problemática, uma alternativa é promover esse enriquecimento por meio de adaptações dos recursos já presentes em aviários comerciais típicos, proporcionando melhores condições de vida, de desempenho e expressão natural do comportamento, favorecendo o BEA.

A negligência com a manutenção das estruturas e equipamentos foi observada desde os aviários até o abate das aves. Foram identificados variados pontos vulneráveis relativos ao BEA em toda a cadeia produtiva, todos apontados pelos participantes no questionário aplicado. As consequências advindas de tais pontos críticos pesam tanto sobre o BEA quanto sobre a produtividade, o que não deixa margem a dúvidas da necessidade de mudanças na cadeia produtiva e novas reflexões sobre a forma mais adequada de criar frangos e produzir carne, considerando o comportamento e a fisiologia dos animais.

Perante os resultados encontrados e procedida a análise crítica dos mesmos, infere-se que a aplicação de técnicas de BEA é praticamente inexistente nas granjas e frigoríficos amostrados, contudo, exequível, dependendo da determinação dos responsáveis pela sua implantação.

\section{REFERÊNCIAS}

1. Kohler F. Antropologia e etologia: uma abordagem conceitual. Rev Antropol UFSCar [Internet]. 2015 [cited 2019 Oct 13];7(1):170-92. Available from: http://www.rau.ufscar.br/wp-content/uploads/2016/09/09_rau07107.pdf

2. Thomas K. O homem e o mundo natural. São Paulo: Companhia das Letras; 2010.

3. Silva PPD, Mendonça ND. Aspectos jurídicos do bem-estar animal. Fragm Cult. 2014;24(esp):19-30. doi: 10.18224/frag.v24i0.3398.

4. Broom DM. Bem-estar animal. In: Yamamoto ME, Volpato GL, editores. Comportamento animal. 2a ed. Natal: Editora da UFRN; 2011. p.457-82.

5. Souza LFA, Massaranduba NT, Ruiz IA, Gomes AS, Costa APS, Silva AFG. Desempenho, rendimento de carcaça e comportamento de frangos de corte criados em cama de maravalha ou areia. Colloq Agrariae. 2016;12(2):6-11. doi: 10.5747/ca.2016.v12.n2.a134.

6. Souza APO, Soriano VS, Schnaider MA, Rucinque DS, Molento CFM. Development and refinement of three animal-based broiler chicken welfare indicators. Anim Welf. 2018;27(3):263-74. doi: 10.7120/09627286.27.3.263.

7. Jung L, Knierim U. Differences between feather pecking and non-feather pecking laying hen flocks regarding their compliance with recommendations for the prevention of feather pecking - a matched concurrent case-control design. Appl Anim Behav Sci. 2019;219:104839. doi: 10.1016/j.applanim.2019.104839.

8. Oliveira GS, Santos VM, Rodrigue JC, Nascimento ST. Protótipo para o estudo do comportamento e da zona de conforto térmico de frangos de corte. Rev Eixo. 2019;8(1):236-45. doi: 10.19123/eixo.v8i1.658.

Lima TF, Stella AE, Silva FB, Pádua GT. Bem-estar animal: Caracterização da ambiência e do manejo na produção e abate de frangos de corte. Vet. e Zootec. 2020; 27: 001-015. 
9. Schiassi L, Yanagi Junior T, Ferraz PFP, Campos AT, Silva GR, Abreu LHP. Comportamento de frangos de corte submetidos a diferentes ambientes térmicos. Eng Agric. 2015;35(3):390-6. doi: 10.1590/1809-4430-Eng.Agric.v35n3p390-396/2015.

10. Riber AB. Effects of color of light on preferences, performance, and welfare in broilers. Poult Sci. 2015;94(8):1767-75. doi: 10.3382/ps/pev174.

11. Barbosa Filho JA, Silva IJO, Silva MAN, Silva CJM. Avaliação dos comportamentos de aves poedeiras utilizando sequência de imagens. Eng Agric. 2007;27(1):93-9. doi: 10.1590/S0100-69162007000100002.

12. Baracho MS, Nääs IA, Lima NDS, Cordeiro AFS, Moura DJ. Factors affecting broiler production: a meta-analysis. Rev Bras Cienc Avic. 2019;21(3):1-10. doi: 10.1590/18069061-2019-1052.

13. Sheikh IU, Nissa SS, Zaffer B, Bulbul KH, Akand AH, Ahmed HÁ, et al. Ammonia production in the poultry houses and its harmful effects. Int J Vet Sci Anim Husb. 2018;3(4):30-3. doi: 10.1007/s11356-018-2018-y.

14. Hernandez RO, Tinoco IFF, Saraz JAO, Souza CF, Coelho DJR, Sousa FC. Calidad del aire en galpón avícola con ventilación natural

durante la fase de pollitos. Rev Bras Eng Agric Ambient. 2016;20(7):660-5. doi: 10.1590/1807-1929/agriambi.v20n7p660-665.

15. Batista M, Neitzel I. Simulação de um aviário: uma análise das condições de conforto para as aves. Rev Tec-Cient CREA-PR [Internet]. 2018 [cited 2020 Apr 10]:1-17. Available from: http://creaprw16.creapr.org.br/revista/Sistema/index.php/revista/article/view/473

16. Ro KS, Li H, Hapeman CJ, Harper LA, Flesch TK, Downey PM, et al. Enhanced dispersion and removal of ammonia emitted from a poultry house with a vegetative environmental buffer. Agriculture. 2018;8(46):1-11. doi:10.3390/agriculture8040046.

17. Zarnab S, Chaudhary MS, Javed MT, Khatoon A, Saleemi MK, Ahmed T, et al. Effects of induced high ammonia concentration in air on gross and histopathology of different body organs in experimental broiler birds and its amelioration by different modifiers. Pak Vet J. 2019;39(3):371-6. doi: 10.29261/pakvetj/2019.068.

18. Rault J-L, Clark K, Groves PJ, Cronin GM. Light intensity of 5 or 20 lux on broiler behavior, welfare and productivity. Poult Sci. 2017;96(4):779-87. doi: $10.3382 / \mathrm{ps} /$ pew 423 .

19. Oliveira RG, Lara LJC. Lighting programmes and its implications for broiler chickens. World's Poult Sci J. 2016;72(4):735-42. doi: 10.1017/S0043933916000702.

20. Jones PJ, Tahamtani FM, Pedersen IJ, Niemi JK, Riber AB. The productivity and financial impacts of eight types of environmental enrichment for broiler chickens. Animals. 2020;10(378):1-14. doi:10.3390/ani10030378.

Lima TF, Stella AE, Silva FB, Pádua GT. Bem-estar animal: Caracterização da ambiência e do manejo na produção e abate de frangos de corte. Vet. e Zootec. 2020; 27: 001-015. 
21. Paul ES, Edgar JL, Caplen G, Nicol CJ. Examining affective structure in chickens: valence, intensity, persistence and generalization measured using a Conditioned Place Preference Test. Appl Anim Behav Sci. 2018;207:39-48. doi: 10.1016/j.applanim.2018.07.007.

22. Ricci GD, Titto CG, Souza RT. Enriquecimento ambiental e bem-estar na produção animal. Rev Cienc Agrovet. 2017;16(3):324-31. doi: 10.5965/223811711632017324.

23. Tahamtani FM, Pedersen IJ, Toinon C, Riber AB. Effects of environmental complexity on fearfulness and learning ability in fast growing broiler chickens. Appl Anim Behav Sci. 2018;207:49-56. doi: 10.1016/j.applanim.2018.04.005.

24. Bach MH, Tahamtani FM, Pedersen IJ, Riber AB. Effects of environmental complexity on behaviour in fast-growing broiler chickens. Appl Anim Behav Sci. 2019;219:104840. doi: 10.1016/j.applanim.2019.104840.

25. Pedersen IJ, Tahamtani FM, Forkman B, Young JF, Poulsen HD, Riber AB. Effects of environmental enrichment on health and bone characteristics of fast growing broiler chickens. Poult Sci. 2020;99(4):1946-55. doi: 10.1016/j.psj.2019.11.061.

26. Baxter M, Richmond A, Lavery U, O'Connell NE. Investigating optimal levels of platform perch provision for windowed broiler housing. Appl Anim Behav Sci. 2020;225:1-29. doi: 10.1016/j.applanim.2020.104967.

27. Pedersen IJ, Forkman B. Improving leg health in broiler chickens: a systematic review of the effect of environmental enrichment. Anim Welf. 2019;28(2):215-30. doi: 10.7120/09627286.28.2.215.

28. Wolff I, Klein S, Rauch E, Erhard M, Mönch J, Härtle S, et al. Harvesting-induced stress in broilers: comparison of a manual and a mechanical harvesting method under feld conditions. Appl Anim Behav Sci. 2019;221:1-12. doi: 10.1016/j.applanim.2019.104877.

29. Lima VA, Ceballos MC, Gregory NG, Costa MJRP. Effect of different catching practices during manual upright handling on broiler welfare and behavior. Poult Sci. 2019;98(10):4282-9. doi: 10.3382/ps/pez284.

30. Braga JS, Macitelli S, Lima VA, Diesel T. O modelo dos "Cinco Domínios" do bem-estar animal aplicado em sistemas intensivos de produção de bovinos, suínos e aves. Rev Bras Zoocienc. 2018;19(2):204-26. doi: 10.34019/2596-3325.2018.v19.24771.

31. Jacobs L, Delezie E, Duchateau L, Goethals K, tuyttens FAM. Broiler chickens dead on arrival: associated risk factors and welfare indicators. Poult Sci. 2017;96(2):259-65. doi: $10.3382 / \mathrm{ps} /$ pew353.

32. Grandin T. On-farm conditions that compromise animal welfare that can be monitored at the slaughter plant. Meat Sci. 2017;132:52-5. doi: 10.1016/j.meatsci.2017.05.004.

33. Humane Farm Animal Care. Padrões do HFAC para a produção de Frango de Corte [Internet]. Herndon: HFAC; 2014 [cited 2019 Oct 13]. Available from: 
https://certifiedhumanebrasil.org/wp-content/uploads/2016/10/Std14-Frangos-de-CorteChickens-2L.pdf

34. Jong IC, Voorst S, Ehlhardt DA, Blokhuis HJ. Effects of restricted feeding on physiological stress parameters in growing broiler breeders. $\mathrm{Br}$ Poult Sci. 2002;43(2):157-68. doi: 10.1080/00071660120121355.

35. Vieira FMC, Silva IJO, Barbosa Filho JAD, Vieira AMC. Influência das condições térmicas do galpão de espera climatizado na mortalidade pré-abate de frangos de corte. Arq Bras Med Vet Zootec. 2016;68(2):475-82. doi: 10.1590/1678-4162-7872.

36. Tavernari FC, Albino LFT, Araújo WAG. Manejo pré-abate de frangos de corte. Rev CFMV [Internet]. 2012 [cited 2019 Oct 15];18(56):62-8. Available from: https://www.embrapa.br/suinos-e-aves/busca-de-publicacoes//publicacao/944223/manejo-pre-abate-de-frangos-de-corte

37. Fuseini A, Teye M, Wotton SB, Lines JÁ, Knowles TG. Electrical water bath stunning for Halal poultry meat production: animal welfare issues and compatibility with the Halal rules. CAB Rev. 2018;13(16):1-7. doi: 10.1079/PAVSNNR201813016.

38. Ludtke CB, Ciocca JRP, Dandin T, Barbalho PC, Vilela JA, Ferrarrini C. Abate humanitário de aves [Internet]. Rio de Janeiro: WSPA; 2010 [cited 2019 Nov 25]. Available from: https://certifiedhumanebrasil.org/wp-content/uploads/2018/12/ProgramaSTEPS-Abate-Humanit\%C3\%A1rio-de-Aves.pdf

39. Royal Society for the Prevention of Cruelty to Animals. RSPCA welfare standards for meat chickens [Internet]. West Sussex: Southwater; 2017 [cited 2020 Apr 11]. Available from: https://science.rspca.org.uk/sciencegroup/farmanimals/standards/chickens

40. Brasil. Ministério da Agricultura, Pecuária e Abastecimento. Portaria no 210, de 10 de Novembro de 1998. Regulamento técnico da inspeção tecnológica e higiênico sanitária de carne de aves. Diário Oficial da União. 26 Nov 1998; sec. 1, p. 226.

41. Novoa M, Vázquez L, Lage A, González-Torres I, Pérez-Garcia LF, Cobas N, et al. Water-bath stunning process in broiler chickens: effects of voltage and intensity. Span J Agric Res. 2019;17(2):1-8. doi: 10.5424/sjar/2019172-14576.

42. Yardimci M. Comparison of the stunning and non-stunning slaughtering methods in the light of the current knowledge. J Vet Anim Res. 2019;2(3):1-5.

43. Barbosa RL, Adamczuk GO, Dvojatzki P, Trentin MG, Lima JD. Efficiency of electrical stunning by electronarcosis: current situation and perspective of improvement in a medium-size processing plant. Rev Bras Cienc Avic. 2016;18(2):331-6. doi: 10.1590/1806-9061-2015-0113.

44. Mackie N, McKeegana DEF. Behavioural responses of broiler chickens during low atmospheric pressure stunning. Appl Anim Behav Sci. 2016;174:90-8. doi: 10.1016/j.applanim.2015.11.001. 
45. Pinto MF, Bitencourt DA, Ponsano EHG, Garcia Neto M, Bossolani ILC. Effect of electrical and controlled atmosphere stunning methods on broiler chicken behavior at slaughter, blood stress indicators and meat traits. Braz J Vet Res Anim Sci. 2016;53(4):18. doi: 10.11606/issn.1678-4456.bjvras.2016.84551.

46. Zanetti M, Surdi GH, Carminatti L, Marangoni A, Bolzan TS. Efeitos de ondas elétricas complexas na insensibilização de frangos para atendimento do Regulamento (CE) 1099/2009. Magistra [Internet]. 2017 [cited 2020 Mar 18];29(1):91-7. Available from: https://magistraonline.ufrb.edu.br/index.php/magistra/article/view/501

47. Sabow AB, Nakyinsige K, Adeyemi KD, Sazili AQ, Johnson CB, Webster J, et al. High frequency pre-slaughter electrical stunning in ruminants and poultry for halal meat production: a review. Livest Sci. 2017;202:124-134. doi: 10.1016/j.livsci.2017.05.021.

48. Zulkifli I, Wakiman Z, Sazili AQ, Goh YM, Jalila A, Zunita Z, et al. Effect of shackling, electrical stunning and halal slaughtering method on stress linked hormones in broilers. $S$ Afr J Anim Sci. 2019;49(3):598-603. doi: 10.4314/sajas.v49i3.20.

49. Aghwan ZA, Bello AU, Abubakar AA, Imlan JC, Sazili AQ. Efficient halal bleeding, animal handling, and welfare: a holistic approach for meat quality. Meat Sci. 2016;121:420-8. doi: 10.1016/j.meatsci.2016.06.028.

50. Wigham E, Grist A, Mullan S, Wotton S, Butterworth A. The influence of welfare training on bird welfare and carcass quality in two commercial poultry primary processing plants. Animals. 2019;9(8):1-20. doi: 10.3390/ani9080584.

Recebido em: 17/07/2020 Aceito em: 22/10/2020 